\title{
BMJ Open Randomised controlled trial for high- dose intravenous zinc as adjunctive therapy in SARS-CoV-2 (COVID-19) positive critically ill patients: trial protocol
}

\author{
Marlon Perera (D) , John El Khoury, ${ }^{1}$ Vidyasagar Chinni, ${ }^{1}$ Damien Bolton, ${ }^{1}$ \\ Liang Qu, ${ }^{1}$ Paul Johnson, ${ }^{2}$ Jason Trubiano (D) , ${ }^{2}$ Christine F McDonald, ${ }^{3}$ \\ Daryl Jones, ${ }^{4,5}$ Rinaldo Bellomo, ${ }^{4,5}$ Oneel Patel, ${ }^{1}$ Joseph Ischia ${ }^{1}$
}

To cite: Perera M, El Khoury J, Chinni V, et al. Randomised controlled trial for high-dose intravenous zinc as adjunctive therapy in SARS-CoV-2 (COVID-19) positive critically ill patients: trial protocol. BMJ Open 2020;10:e040580. doi:10.1136/ bmjopen-2020-040580

- Additional material is published online only. To view please visit the journal online (http://dx.doi.org/10.1136/ bmjopen-2020-040580).

Received 19 May 2020 Revised 27 0ctober 2020 Accepted 05 November 2020

Check for updates

(c) Author(s) (or their employer(s)) 2020. Re-use permitted under CC BY-NC. No commercial re-use. See rights and permissions. Published by BMJ.

For numbered affiliations see end of article.

Correspondence to

Marlon Perera;

marlonlperera@gmail.com

\section{ABSTRACT}

Introduction SARS-CoV-2 (COVID-19) has caused an international pandemic of respiratory illness, resulting in significant healthcare and economic turmoil. To date, no robust vaccine or treatment has been identified. Elemental zinc has previously been demonstrated to have beneficial effects on coronaviruses and other viral respiratory infections due to its effect on RNA polymerase. Additionally, zinc has well-demonstrated protective effects against hypoxic injury-a clear mechanism of end-organ injury in respiratory distress syndrome. We aimed to assess the effect of high-dose intravenous zinc (HDIVZn) on SARS-CoV-2 infection. The end of study analyses will evaluate the reduction of impact of oxygen saturations or requirement of oxygen supplementation.

Methods and analysis We designed a double-blind randomised controlled trial of daily HDIVZn $(0.5 \mathrm{mg} / \mathrm{kg})$ versus placebo. Primary outcome measures are lowest oxygen saturation (or greatest level of supplemental oxygenation) for non-ventilated patients and worst $\mathrm{PaO}_{2} /$ $\mathrm{FiO}_{2}$ for ventilated patients. Following power calculations, 60 hospitalised patients and 100 ventilated patients will be recruited to demonstrate a $20 \%$ difference. The duration of follow-up is up to the point of discharge.

Ethics and dissemination Ethical approval was

obtained through the independent Human Research Ethics Committee. Participant recruitment will commence in May 2020. Results will be published in peer-reviewed medical journals.

Trial registration number ACTRN126200000454976.

\section{INTRODUCTION}

Since December 2019, a new coronavirus, designated SARS-CoV-2, has caused an international pandemic of respiratory illness termed COVID-19, posing significant threats to global health and the economy. ${ }^{1-3}$ In more severe cases, COVID-19 enters the lungs, causing respiratory complications such as bronchitis and pneumonia. ${ }^{45}$ Development of pneumonia leads to a reduced ability for

\section{Strengths and limitations of this study}

- This is the first trial designed primarily to assess the effect of high-dose intravenous zinc in SARS-CoV-2.

- A strength of this study is its randomised, doublebling, placebo controlled nature of the study design.

- This is an adequately powered study with objective, universal primary and secondary outcome measures.

- Potential limitations pertain to conducting the current study in Australia, a country with a relatively low prevalence of COVID-19 with a risk of under recruitment.

oxygenation and in some cases, the development of acute respiratory distress syndrome, requiring mechanical ventilation. In the most severe cases, patients can develop multiple organ failure and hypoxic brain injury. In the absence of an effective vaccine or robust treatment for people with the disease,${ }^{6}$ there is an urgent need to find a treatment that inhibits virus replication or reduces the progression of the disease.

Zinc is a naturally occurring essential heavy metal, and zinc deficiency is associated with a range of pathological conditions, including retarded growth and delayed wound healing and tissue repair. Zinc is also important for the maintenance and development of the immune system and plays a role in cell division and growth. Zinc deficiency results in reduced immunity and increases susceptibility to infectious diseases. ${ }^{78}$ Numerous studies report the potential of zinc and zinc salts to inhibit viral infections in clinical and experimental settings. Viral infections that have been successfully inhibited by zinc include the common cold (a type 
of coronavirus), ${ }^{9}$ respiratory syncytial virus infections, ${ }^{10}$ cytomegalovirus infections ${ }^{11}$ and herpes labialis. ${ }^{12}$ More importantly, zinc is a potent inhibitor of the replication of SARS-coronavirus (SARS-CoV) and equine arteritis virus in cell culture. ${ }^{13}$

Furthermore, our published studies have shown that high-dose intravenous zinc (HDIVZn) protects various organs, including the heart, kidneys and liver against the damage caused by hypoxia. ${ }^{71-16}$ In addition to being efficacious, the dose of elemental zinc used for this HDIVZn trial $\left(0.25 \mathrm{mg} / \mathrm{kg}(0.5 \mathrm{mg} / \mathrm{kg} \mathrm{ZnCl})_{2}\right)$ and applied in our preclinical study in sheep is very safe and well-tolerated in humans as verified from multiple observational reports including the treatment of very sick children in an intensive care unit (ICU) setting with suspected zinc deficiency. ${ }^{17-20}$

We plan to perform a single-site randomised controlled trial to test the efficacy and safety of HDIVZn administered as a daily injection in subjects with COVID-19 infection to assess whether giving HDIVZn to patients improves clinical outcomes.

\section{METHODS AND DESIGN}

Ethical approval was sought through the Austin Health institutional Human Research Ethics Committee (Version 2, 4 April 2020). Any modifications to the trial protocol will be approved prospectively by the associated Ethical Committee. This clinical trial was registered with Australian New Zealand Clinical Trials Registry (ACTRN126200000454976). The protocol design was produced in adherence with the Standard Protocol Items for Randomised Trials. ${ }^{21}$ No external funding was sought for the completion of this project.

\section{Patient and public involvement}

The development of the research question stemmed from the urgent global crisis inflicted by COVID-19, and the urgent need for a therapy to reduce the impact of the disease on the affected patients. Patients were not intrinsically involved in the design, recruitment or conduct of the study. Results of the study will be disseminated to patients after publication in peer-review journal. While the burden of the treatment or placebo was not assessed directly by patients, it was deemed minimal due to the lack of deviation from standard care.

\section{Study design}

This is a phase 2, double-blind, placebo-controlled, randomised study at a single institution. The study plans to randomise 160 hospitalised participants, including 100 critically ill patients with confirmed COVID-19 (as detailed in table 1) and to evaluate the efficacy and safety of HDIVZn over a 7-day period of treatment.

\section{Dosing rationale}

The upper limit for daily zinc intake in an adult is $40 \mathrm{mg}{ }^{22}$ However, when $30 \mathrm{mg}$ of elemental zinc was given orally to humans, it resulted in an only 1.8-fold increase in plasma zinc in the first 4 hours. ${ }^{23} \mathrm{~A}$ similar study in humans where elemental zinc $(30 \mathrm{mg} / \mathrm{d})$ or placebo were given orally for 6 months showed a statistically significant in the plasma zinc from $14.18 \pm 1.75 \mu \mathrm{mol} / \mathrm{L}$ in the placebo group to $17.18 \pm 3.48 \mu \mathrm{mol} / \mathrm{L}$ in the zinc group. ${ }^{24}$ Oral delivery of zinc is affected by several factors, including normal variations in gut zinc absorption, dietary factors such as the presence of phytate, and interactions with other metal ions. ${ }^{25}$ Also, repeated high oral zinc intake causes a rapid and significant upregulation of intestinal metallothioneins (MTs) which markedly decrease subsequent gut zinc, and importantly copper, absorption. ${ }^{26}$ The latter may lead to copper deficiency in patients administered zinc for prolonged periods.

In our recently published sheep study, we determined that a single IV dose of $\mathrm{ZnCl}_{2}$ at $0.5 \mathrm{mg} / \mathrm{kg}$ increased the plasma zinc concentration by fourfold from a baseline concentration of $11.3 \pm 0.4 \mu \mathrm{mol} / \mathrm{L}$ to $46.5 \pm 1.5 \mu \mathrm{mol} / \mathrm{L}$ within 2 hours. ${ }^{14}$ Interestingly, two doses of IV $\mathrm{ZnCl}_{2}$ at $0.5 \mathrm{mg} / \mathrm{kg}$ increased the plasma zinc concentration sevenfold from a baseline concentration of $11.3 \pm 0.4 \mu \mathrm{mol} / \mathrm{L}$ to $70.1 \pm 5.8 \mu \mathrm{mol} / \mathrm{L}$.

Translation of a drug's dose from animals to humans depends on the drug dose correction factor $\left(\mathrm{K}_{\mathrm{m}}\right)$ which is calculated by dividing the average body weight $(\mathrm{kg})$ of a species by its body surface area $\left(\mathrm{m}^{2}\right)$. For humans, $\mathrm{K}_{\mathrm{m}}$ is $37{ }^{27}$ Direct carryover of a drug's pharmacologic dosage, from animals to humans depends on how similar the $\mathrm{K}_{\mathrm{m}}$ value of the animal species in which efficacy was tested, is to human $\mathrm{K}_{\mathrm{m}}$. As published by Nair and Jacob, ${ }^{27} \mathrm{~K}_{\mathrm{m}}$ for rats is 6 , for rabbits is 12 and for sheep is 36 (average body weight of sheep is $40 \mathrm{~kg}$, and body surface area is $1.10 \mathrm{~m} 2) .{ }^{28}$ Therefore, the near similar $\mathrm{K}_{\mathrm{m}}$ value of sheep (36) to that of humans (37) has allowed us to conclude that human equivalent elemental zinc dosage would equate to $0.25 \mathrm{mg} / \mathrm{kg}$, the same dose that was shown to be protective in the sheep study and which we plan to use in our proposed trial.

Information regarding the safety of HDIVZn can be derived from published reports where humans were treated with high doses of zinc. ${ }^{17-20}$ The estimated elemental HDIVZn dosage for an average $70 \mathrm{~kg}$ human to be used in our proposed study will be $0.25 \mathrm{mg} / \mathrm{d}$ x $70 \mathrm{~kg}=17 \mathrm{mg} / \mathrm{d}$. Elemental zinc has been administered at a substantially higher dose (ranging from 26.4 to $37.5 \mathrm{mg} / \mathrm{d}$ for 8 successive days) in the treatment of human burns without any side effects. ${ }^{17-19}$ In fact, zinc at doses ranging from 5 to $22 \mathrm{mg} / \mathrm{d}$ has been administered in humans routinely as a component of parenteral nutrition without any reported side effects. ${ }^{29}$ Furthermore, a recently published phase I clinical trial in critically ill children with suspected zinc deficiency involved administration of zinc intravenously at a dose of three times higher than is proposed in the current study $(0.75 \mathrm{mg} / \mathrm{kg} / \mathrm{d}$ for 7 days), without any adverse effects. ${ }^{20}$

The duration of daily dosing in the current trial was based on previous research assessing dose escalation of 
Table 1 Inclusion and exclusion criteria

\begin{tabular}{|c|c|}
\hline Inclusion criteria & Exclusion criteria \\
\hline 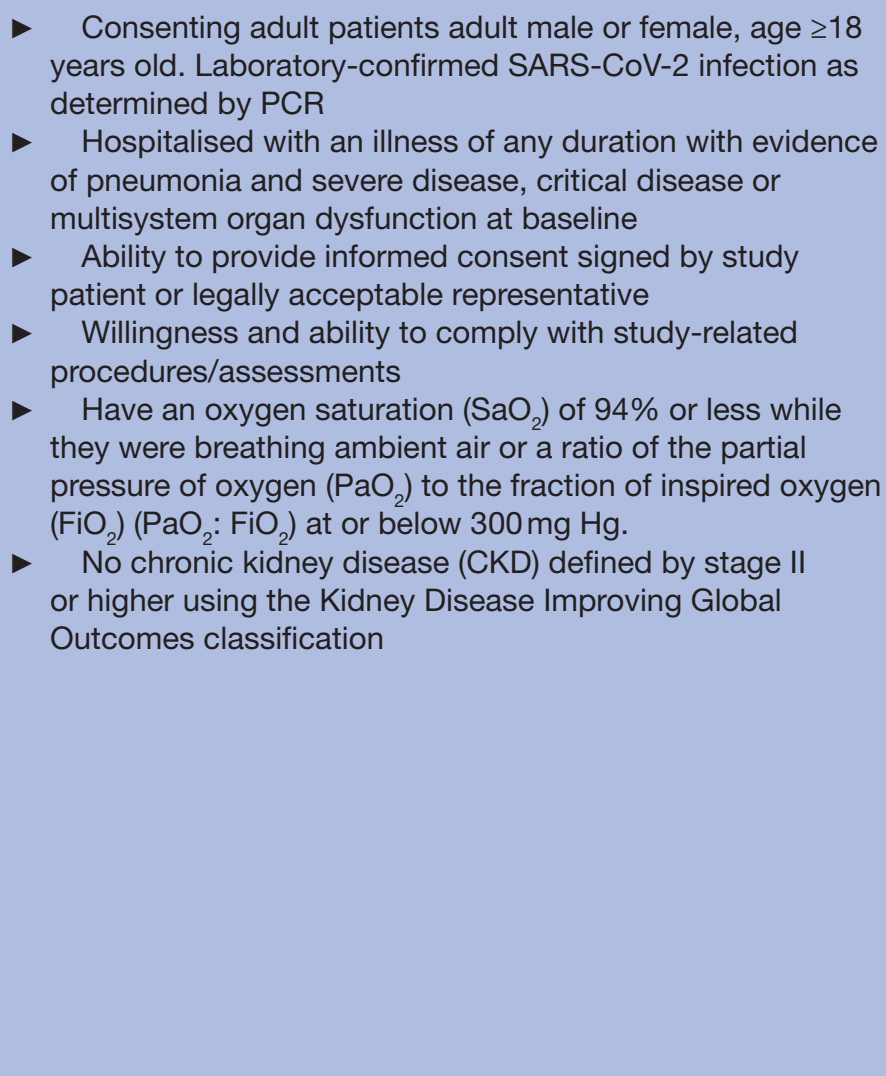 & $\begin{array}{l}\text { Age }<18 \text { or pregnant or lactating female } \\
\text { Allergy to zinc } \\
\text { Severe hepatic impairment defined as Child C liver } \\
\text { disease. } \\
\text { eGFR } \leq 60 \mathrm{~mL} / \mathrm{min} / 1.73 \mathrm{~m}^{2} \text { (defined using CKD-EPI SCr } \\
\text { formula) } \\
\text { History of any organ transplant which requires active } \\
\text { immunosuppressive treatment which can interfere with } \\
\text { kidney function } \\
\text { If a patient required any of the following within } 7 \text { days } \\
\text { prior to cardiac surgery: defibrillation, mechanical } \\
\text { ventilation, left ventricular assist device or other forms of } \\
\text { mechanical circulatory support } \\
\text { If a patient required cardiopulmonary resuscitation within } \\
\text { 14 days } \\
\text { Do not resuscitate and do not intubate orders } \\
\text { Death is deemed imminent or inevitable during this } \\
\text { admission, and either the attending physician, patient } \\
\text { or substitute decision-maker is not committed to active } \\
\text { treatment } \\
\text { Already receiving dialysis (either acute or chronic) or } \\
\text { imminent need of dialysis at the time of enrolment } \\
\text { Patients with known HIV infection } \\
\text { Patients with a known or suspected history of oxalate } \\
\text { nephropathy or hyperoxaluria, scurvy, chronic iron overload, } \\
\text { Plinician expects to prescribe Zinc for another indication } \\
\text { Patients with known haemochromatosis }\end{array}$ \\
\hline
\end{tabular}

CKD-EPI SCr: Chronic kidney disease Epidemiology Collaboration Equation

CKD-EPI SCr, Chronic kidney disease Epidemiology Collaboration Equation; eGFR, estimated glomerular filtration rate.

intravenous supplemental zinc. ${ }^{20}$ This dose escalation study in paediatric critical illness highlighted that with sufficiently high doses of intravenous zinc, a treatment course of 7 days resulted in increases of serum zinc.

\section{PARTICIPANTS AND RANDOMISATION Eligibility}

Patients will be eligible for randomisation in this study if they are consenting symptomatic hospitalised adult patients fulfilling WHO's case definition for COVID-19, including a positive PCR for COVID-19 from any specimen (eg, respiratory, blood, urine, stool, other bodily fluid) within 14 days of presentation. Broadly speaking, patients included will be those with respiratory associated COVID-19 disease. Patients with alternate acute respiratory pathology causing respiratory compromise, such as bacterial pneumonia, will not be deemed suitable for randomisation. Inclusion and exclusion criteria are summarised in table 1. Patients enrolled in the current trial are eligible to be recruited in alternative trials and may receive other therapeutic interventions including dexamethasone or remdesivir.

\section{Screening procedures}

The screening $\log$ is designed to monitor patient recruitment. A screening log will be maintained at the participating site by the research coordinator to document patients evaluated for enrolment. The log will provide a record of all patients assessed for eligibility and deemed ineligible for the study. When a patient is considered ineligible, the reason(s) will be noted on the log. The $\log$ will also be used to assess patient recruitment targets. Patients will be consented by trial investigators by completion of consent and assent forms from the patient directly or surrogates if the patient does not have the ability to consent (online supplemental 1).

\section{Randomisation}

This study will be conducted as a randomised doubleblinded placebo-controlled study using a stratified randomisation method. Ward and ICU patients will be enrolled as soon as possible after fulfilling the criteria of stratification. Consenting patients will be stratified based on whether they require mechanical ventilation. Thereafter, a permuted block randomisation method with variable block sizes of 2, 4 and 6 will be used to allocate eligible patients to either the treatment group, receiving HDIVZn 
or to the control group in a 1:1 ratio. Randomisation will be performed by the randomisation module in Research Electronic Data Capture (REDCap, Vanderbilt University, USA), which is a secure web application for managing online data collection. Patients, clinical staff, outcome assessors and data analysts will be blinded. Assessment of the unblinding procedures by the project research officer in the case of adverse event will be performed if necessary. The clinical staff involved in patient care will administer the trial drugs as soon as possible after enrolment.

\section{Study drug administration and blinding}

Pharmaceutical grade zinc chloride stock solution obtained from an Australian company (Phebra Pty Ltd, Lane Cove West, NSW, Australia) will be diluted in $250 \mathrm{~mL}$ of normal saline and infused, resulting in a final dosage of $0.5 \mathrm{mg} / \mathrm{kg} / \mathrm{d}$. Patients will be administered zinc daily for 7 days. Placebo will be unadjusted $250 \mathrm{~mL}$ of normal saline. To standardise administration time, zinc infusions or control will commence in the early morning. Zinc or placebo will be administered via central venous or peripheral access over 3 hours. Zinc or placebo will be administered daily until either discharge or 7 days of infusion (depending on which is sooner). The clinical trial nurse (allocation concealment) will use a web-based randomisation programme to determine the allocation of patients and then prepare the coded zinc solution or placebo. Each coded solution bag, which will be indistinguishable irrespective of study group, will then be dispensed for administration to the patient as per protocol. This coded identifying study number will also be labelled on the patient case report form (CRF). The investigators, study coordinators, treating physicians, bedside nurses and patients/family will remain blinded to the allocated study solution.

\section{STUDY ASSESSMENT}

\section{Study objective and endpoints}

The endpoints of this study are listed in table 2. The primary objective is to assess the effect of 7 days of HDIVZn on oxygenation in comparison with placebo in patients with confirmed COVID-19. Specifically, oxygen saturations and the requirement of supplemental oxygenation (litres/min) to maintain acceptable saturations will be measured at various time points in conjunction with measurement of routine observations. If applicable, the method of supplemental oxygenation provided will be recorded (eg, nasal prongs, Hudson mask). The primary outcome will be measured by either the highest level of supplemental oxygen (non-ventilated patients) or lowest $\mathrm{PaO}_{2} / \mathrm{FiO}_{2}$ ratio in ventilated patients.

Secondary outcome measures include ICU and in-hospital mortality, length of stay in ICU or hospital, duration of supplemental oxygen, severe adverse drug events and changes based on WHO R\&D Blueprint 'Novel Coronavirus COVID-19 Therapeutic Trial synopsis'. The following is based on an eight-point ordinal scale consisting of:

\section{Table 2 Primary and secondary outcomes}

\begin{tabular}{|c|c|}
\hline Key primary outcome & Key secondary outcomes \\
\hline $\begin{array}{l}\text { Mean change in the highest } \\
\text { level of oxygenation (oxygen } \\
\text { flow measured litre/min) in } \\
\text { non-ventilated patients } \\
\text { Mean change in lowest } \\
\mathrm{PaO}_{2} \text { in ventilated patients }\end{array}$ & $\begin{array}{l}\text { Mortality (ICU or in-hospital) } \\
\text { Duration of mechanical } \\
\text { ventilation } \\
\text { Duration of oxygen therapy } \\
\text { Duration of hospitalisation } \\
\text { Length of stay in ICU }\end{array}$ \\
\hline \multicolumn{2}{|l|}{ Other secondary outcomes } \\
\hline $\begin{array}{l}\text { Adverse drug events } \\
\text { Acute kidney injury } \\
\text { Acute liver injury } \\
\text { Duration of vasopressor } \\
\text { drugs } \\
\text { Sequential organ failure } \\
\text { assessment respiratory } \\
\text { score }\end{array}$ & $\begin{array}{l}\text { Clinical improvement based } \\
\text { on an eight-point ordinal scale } \\
\text { recommended in the document } \\
\text { published by WHO R\&D } \\
\text { Blueprint 'Novel Coronavirus } \\
\text { COVID-19 Therapeutic Trial } \\
\text { Synopsis'. } \\
\text { Percentage of patients } \\
\text { reporting each severity } \\
\text { rating on an eight-point } \\
\text { ordinal scale (time frame: } \\
\text { day 14) } \\
\text { Time to improvement in one } \\
\text { category from admission } \\
\text { using the eight-point ordinal } \\
\text { scale (time frame: up to day } \\
28 \text { ) } \\
\text { Mean change in the eight- } \\
\text { point ordinal scale (time } \\
\text { frame: up to day 28) }\end{array}$ \\
\hline
\end{tabular}

ICU, intensive care unit.

0 , not hospitalised, no clinical or virological evidence of infection;

1 , not hospitalised, infected and able to resume normal activities;

2, not hospitalised, infected, but unable to resume normal activities;

3, hospitalised, no requirement of supplemental oxygen;

4, hospitalised, requiring oxygen therapy via mask or nasal prongs;

5, hospitalised, non-invasive ventilation, requiring high flow oxygen;

6 , hospitalised, intubation and mechanical ventilation;

7, hospitalised, requiring Extracorporeal membrane oxygenation (ECMO), invasive mechanical ventilation, additional organ support, Renal replacement therapy (RRT);

8 , death.

\section{Physical examination, measurements and laboratory tests}

All data will be collected by blinded trained staff using a CRF worksheet developed by the study team. Data will then be entered into the REDCap web database (electronic CRF). Randomised patients will be followed up to discharge, death or 28 days postrandomisation whichever occurs first. 
Table 3 Collected data during trial

\begin{tabular}{|c|c|c|}
\hline & All patients & \\
\hline \multirow[t]{2}{*}{ Baseline data } & $\begin{array}{l}\text { Baseline data } \\
\text { Demographics: age, gender, place of residence } \\
\text { Comorbidities: diabetes mellitus, arterial hypertension, } \\
\text { congestive heart failure, chronic obstructive airways disease, } \\
\text { chronic liver disease, malignancy, chronic renal failure } \\
\text { Preadmission medication } \\
\text { Functional status/frailty score }\end{array}$ & \\
\hline & Non-ventilated patients & Ventilated patients \\
\hline Daily observations & $\begin{array}{l}\text { Daily saturations (worst values) } \\
\text { Daily oxygen flow } \\
\text { Fluid input } \\
\text { Urine output } \\
\text { Fluid balance }\end{array}$ & $\begin{array}{l}\text { Daily } \mathrm{PaO}_{2} / \mathrm{FiO}_{2} \text { ratio } \\
\text { Daily oxygen flow } \\
\text { Fluid input } \\
\text { Urine output } \\
\text { Fluid balance } \\
\text { Vasopressor data }\end{array}$ \\
\hline $\begin{array}{l}\text { Laboratory investigations } \\
\text { (collected at 0800) }\end{array}$ & $\begin{array}{l}\text { Daily serum creatinine } \\
\text { Daily liver function } \\
\text { Daily blood count } \\
\text { Daily zinc and trace metal concentration (copper, potassium, } \\
\text { magnesium) } \\
\text { Daily cardiac troponin } \\
\text { Daily lactate level }\end{array}$ & $\begin{array}{l}\text { Daily serum creatinine } \\
\text { Daily liver function } \\
\text { Daily blood count } \\
\text { Daily zinc and trace metal concentration (copper, } \\
\text { potassium and magnesium) } \\
\text { Daily cardiac troponin } \\
\text { Daily lactate level }\end{array}$ \\
\hline Primary outcome measures & $\begin{array}{l}\text { Mean change in highest level of oxygenation requirement } \\
\text { (oxygen flow in litres/min) }\end{array}$ & $\begin{array}{l}\text { Mean change in lowest } \mathrm{PaO}_{2} / \mathrm{FiO}_{2} \text { ratio (in } \mathrm{mm} \\
\mathrm{Hg} \text { ) }\end{array}$ \\
\hline $\begin{array}{l}\text { Secondary outcome } \\
\text { measures }\end{array}$ & $\begin{array}{l}\text { Mortality (time frame: up to day 28) } \\
\text { Duration of oxygen therapy (days) } \\
\text { Duration of hospitalisation (days) } \\
\text { Length of stay in the intensive care unit (ICU) and hospital } \\
\text { Frequency of serious adverse drug events } \\
\text { Acute kidney injury } \\
\text { Acute liver injury } \\
\text { Time to resolution of fever for at least } 48 \text { hours without } \\
\text { antipyretics by clinical severity } \\
\text { Incidence of severe or life-threatening bacterial, invasive fungal } \\
\text { or opportunistic infection } \\
\text { Number of patients admitted into an ICU (time frame: up to day } \\
28 \text { ) } \\
\text { Sequential organ failure assessment (SOFA) respiratory score } \\
\text { (time frame: } 28 \text { days). Assigned a point value from } 0 \text { (normal) to } \\
4 \text { (high degree of dysfunction/failure) } \\
\text { Clinical improvement based on an eight-point ordinal scale } \\
\text { recommended in the document published by WHO R\&D } \\
\text { Blueprint 'Novel Coronavirus COVID-19 Therapeutic Trial } \\
\text { Synopsis'. } \\
\text { - Percentage of patients reporting each severity rating on an } \\
\text { - eight-point ordinal scale (time frame: day 14) } \\
\text { - Time to improvement in one category from admission using } \\
\text { the eight-point ordinal scale (time frame: up to day 28) } \\
\text { to day } 28 \text { ) }\end{array}$ & $\begin{array}{l}\text { Mortality (time frame: up to day 28) } \\
\text { Duration of mechanical ventilation (days) } \\
\text { Duration of oxygen therapy (days) } \\
\text { Duration of hospitalisation (days) } \\
\text { Length of stay in the ICU and hospital } \\
\text { Frequency of serious adverse drug events } \\
\text { Acute kidney injury } \\
\text { Acute liver injury } \\
\text { Use, duration and dosage of vasopressor drugs } \\
\text { Time to resolution of fever for at least } 48 \text { hours } \\
\text { without antipyretics by clinical severity } \\
\text { Incidence of severe or life-threatening bacterial, } \\
\text { invasive fungal or opportunistic infection } \\
\text { Number of patients admitted into an ICU (time } \\
\text { frame: up to day } 28 \text { ) } \\
\text { SOFA respiratory score (time frame: } 28 \text { days). } \\
\text { Assigned a point value from } 0 \text { (normal) to } 4 \text { (high } \\
\text { degree of dysfunction/failure) } \\
\text { Clinical improvement based on an eight-point } \\
\text { ordinal scale recommended in the document } \\
\text { published by WHO R\&D Blueprint 'Novel } \\
\text { Coronavirus COVID-19 Therapeutic Trial } \\
\text { Synopsis'. } \\
\text { - Percentage of patients reporting each severity } \\
\text { rating on an eight-point ordinal scale (time } \\
\text { frame: day } 14 \text { ) } \\
\text { - Time to improvement in one category from } \\
\quad \text { admission using the eight-point ordinal scale } \\
\text { (time frame: up to day } 28 \text { ) } \\
\text { - Mean change in the eight-point ordinal scale } \\
\text { (time frame: up to day } 28 \text { ) }\end{array}$ \\
\hline
\end{tabular}

Study day 1 commences on randomisation and concludes at the expiry of the calendar day. Data collection will be restricted primarily to those variables necessary to define clinical patient characteristics including baseline demographics, primary diagnoses, physiological parameters, diagnostic interventions, therapeutic interventions and documentation of deaths and other serious adverse events. A complete list of collected data is summarised in table 3. Compliance of study protocol will be monitored by daily checklists confirming administration of trial infusion and collection of laboratory investigation and minimum outcome measures.

Daily patient assessment will be performed to encourage participant retention, completion of infusion and data collection. Further, daily assessment will allow for prompt recognition of adverse effects of the trial intervention.

\section{Adverse events}

An adverse reaction is defined as any untoward and unintended response to an investigational medicinal product 
related to any dose administered. All adverse events judged by either the reporting investigator or the sponsor as having a reasonable possibility of a causal relationship to an investigational medicinal product will qualify as adverse reactions. Adverse events were classified per the Common Terminology Criteria for Adverse Events (CTCAE V.5) ${ }^{30}$ All adverse events which are considered to be potentially causally related to the study intervention or are otherwise of concern in the investigator's judgement will be reported. An interim analysis is planned after $50 \%$ (80) of the patients have been randomised. Development of severe adverse events (grade 4), such as severe kidney or hepatic injury, will result in cessation of the trial for the participant and all infusions related to the trial will be stopped. For patients suffering adverse events, aftercare will be provided by in-hospital specialists units as part of ongoing care. Additionally, the treatment will be discontinued in cases where the participant wishes to withdraw from the trial.

\section{Safety evaluations}

An independent Data Monitoring Committee (DMC), consisting of experts in intensive care, clinical research and biostatistics will be established before patient enrolment and will review all trial protocols. The role of the DMC will be to provide study oversight to ensure that the rights and safety of patients involved in the study are protected by reviewing reported Adverse Events and making recommendations to the Management Committee.

\section{STUDY ANALYSIS}

\section{Sample size}

The primary outcome of this study is related to the effect of zinc therapy on the level of oxygenation expressed either as worst (highest) oxygen flow (in litres/min) in non-ventilated patients or worst (lowest) $\mathrm{PaO}_{2}$ (in $\mathrm{mm}$ $\mathrm{Hg}$ ) $/ \mathrm{FiO}_{2}$ (as a fraction of 1) ratio in ventilated patients. We hypothesise that zinc therapy will decrease the worst level of oxygenation during the 7 days (of the treatment period) by $20 \%$ compared with placebo from a mean worst value of $10 \mathrm{~L} / \mathrm{min}$ (placebo) to a mean of $8 \mathrm{~L} / \mathrm{min}$ (zinc) or for $\mathrm{PaO}_{2} / \mathrm{FiO}_{2}$ ratio from a mean worst value of 150 (placebo) to a mean worst value of 180 (zinc). If patients transition from non-ventilated to ventilated during the study period, the $\mathrm{PaO}_{2} / \mathrm{FiO}_{2}$ ratio will be used.

To have an $80 \%$ power to see such an effect at an alpha of 0.05 in non-ventilated patients, assuming a SD for $\mathrm{O}_{2}$ flow of $2.5 \mathrm{~L} / \mathrm{min}, 25$ patients would have to be randomised in each arm. In ventilated patients, to have an $80 \%$ power to see such an effect at an alpha of 0.05 , assuming an $\mathrm{SD}$ for the $\mathrm{PaO}_{2} / \mathrm{FiO}_{2}$ ratio of 50, 44 patients would have to be randomised in each arm.

Rounding off the first group to 30 per arm and the second group to 50 per arm to account for withdrawals, we estimate that a study of 160 patients would provide a suitable sample size to test our primary hypothesis.

\section{Statistical evaluation}

Deidentified data will be extracted to an Microsoft Excel 2019 (Redmond, Washington, USA) and will be made available to trial investigators, senior statisticians and the principal investigator. The descriptive analysis of the data will include the calculation of summary statistics including means, SD and absolute and relative frequencies of the baseline and follow-up data. If baseline variables are not approximately normally distributed, suitable transformations or medians with interquartile ranges will be presented. Any baseline variable, differing by greater than $10 \%$ or 0.5 SD between arms, will be subsequently investigated in a sensitivity analysis.

Any continuous variable outcomes that appear to be non-normal will be considered for transformation to improve normality of the residuals for subsequent regression analysis. Transformation will depend on distribution of the variable, distribution of residuals, ease of interpretation and impact on main results. The coprimary outcome analyses will compare (1) the change in highest level of supplemental oxygenation in non-ventilated patients, and (2) the change in lowest $\mathrm{PaO}_{2} / \mathrm{FiO}_{2}$ ratio in ventilated patients through the use of multivariable linear regression. Secondary outcome analyses will involve a mix of linear, logistic and ordinal logistic regression modelling. Assumptions of the relevant models will be checked along with alternative transformations or non-parametric methods as appropriate.

Tests of interaction between dichotomised variables and treatment pathway will be carried out to test for differing treatment effect between participants. Sensitivity analyses will be conducted to explore the robustness of the estimate of the effect. Analyses will include complete case analysis; per-protocol analysis, adjustment for baseline and adjustment for imbalance at baseline (if baseline measures differ substantially).

A p-value 0.05 will indicate statistical significance. A full model with clinical relevant covariates (eg, sex, age, previous heart surgery, preoperative creatinine) will be used for a stepwise backward variable selection procedure to identify independent risk factors for acute kidney injury. A senior statistician will perform data analysis on an intention-to-treat basis. An interim analysis on the safety and the primary outcomes will be performed when $50 \%$ $(80 / 160)$ of the patients have received zinc or placebo for at least 7 days. Summary statistics will be used to describe the clinical data and presented as mean $\pm \mathrm{SD}$, median with $\mathrm{IQR}$ or percentages as appropriate. Chi-squared analysis with Fisher's exact test (when appropriate) and Student's t-test (Mann Whitney U test for non-normal distributions) will be used to compare data between the active treatment group and the control group with statistical significance declared for probability values of 0.05 or less. Analysis of the outcome of excluded patients due to other trials will be in accordance with the Consolidated Standards of Reporting Trials guidelines. Statistical coding will be made on request. 
Findings will be published in peer-review journals. Eligible authors will include trial investigators, principal investigator, statisticians and clinicians involved in manuscript preparation.

\section{DISCUSSION}

This single-centre, double-blind, randomised controlled trial will assess the role of HDIVZn in protection against the sequelae associated with SARS-CoV-2 virus. The beneficial effects of zinc on viral infections have been previously demonstrated. ${ }^{31}{ }^{32}$ Further, HDIVZn may provide additional protection to other end organs that may be indirectly affected by pulmonary injury and impaired oxygenation.

In coronaviruses, zinc inhibits both the proteolytic processing of replicase polyproteins and the RNAdependent RNA polymerase (RdRp) activity. ${ }^{13}$ Although mechanisms of action of zinc are unknown, several possibilities exist. First, DNA and RNA polymerases use divalent metal ions like $\mathrm{Mg}^{2+}$ as a cofactor, and one possible mechanism is that zinc displaces $\mathrm{Mg}^{2+}$ and subsequently inhibits RdRp activity. ${ }^{33}$ In support is the observation that various divalent metals ions sustained the activity of poliovirus $\mathrm{RdRp}$ in the following preference $\mathrm{Mn}^{2+}>\mathrm{Co}^{2+}>\mathrm{Ni}^{2+}>$ $\mathrm{Fe}^{2+}>\mathrm{Mg}^{2+}>\mathrm{Ca}^{2+}>\mathrm{Cu}^{2+} \cdot{ }^{34}$ In contrast, zinc was incapable of sustaining RdRp catalysed nucleotide incorporation. ${ }^{34}$ Second, a zinc-binding pocket has been identified in the Dengue virus and SARS-coronavirus RdRp. ${ }^{13}$ Therefore, it is possible that binding of zinc may induce a structural change in the conformation of RdRp which disables RdRp to catalyse nucleotide incorporation. Finally, adding high concentrations of zinc ions to cells impairs viral polyprotein processing which is integral to virus replication. ${ }^{35}$

In addition to the direct effect on viral replication and activity, HDIVZn may play a protective role in alternate organs. Zinc has been demonstrated to be beneficial in reducing mortality in patients with severe pneumonia. ${ }^{36}$ Further, in SARS-CoV-2, respiratory compromise results in impaired oxygenation and hypoxia to various end organs. Such hypoxia may contribute to end-organ failure and increase the risk of mortality. Specifically, such COVID-19 associated hypoxia has been proposed to be contributory to cardiac injury, ${ }^{37}$ hepatic injury ${ }^{38}$ and renal injury. ${ }^{39} 40$ Our published studies have shown that HDIVZn protects various organs, including the heart, kidneys and liver against the damage caused by hypoxia. It should be noted that hypoxia and oxidative stress, result in an increase in reactive oxygen species (ROS), including superoxide $\left(\mathrm{O}_{2}^{-}\right)$, hydrogen peroxide $\left(\mathrm{H}_{2} \mathrm{O}_{2}\right)$ and hydroxyl radical $(\cdot \mathrm{OH})$-which result in intracellular damage. ${ }^{41}{ }^{42} \mathrm{Zinc}$ appears to limit ROS production by several mechanisms. First, MTs, small cysteine-rich and heavy metal-binding proteins, participate in the intracellular defence against reactive oxygen and nitrogen species ${ }^{43}$ and zinc has been shown to induce MT mRNA and protein expression. Second, zinc competes with $\mathrm{Fe}^{2+}$ and $\mathrm{Cu}^{2+}$ ions for binding to cell membranes and proteins-normally, these active metals catalyse the production of hydroxyl radical from $\mathrm{H}_{2} \mathrm{O}_{2}$ via Fenton chemistry. Third, zinc upregulates the production and activation of antioxidant proteins, molecules and enzymes such as glutathione, catalase and superoxide dismutase, which catalyse $\mathrm{O}_{2}{ }^{-}$to oxygen or $\mathrm{H}_{2} \mathrm{O}_{2} \cdot{ }^{44}$ Finally, zinc reduces the activation of oxidant-promoting enzymes such as inducible nitric acid synthase and NADPH enzyme, which catalyse oxygen to $\mathrm{O}_{2}^{-}$. Accordingly, we hypothesise that Zinc may provide protection against the hypoxic injury that critically ill patients with COVID-19 may experience.

The specific strengths of the current protocol design are (a) prolonged exposure of HDIVZn and (b) assessment of critically ill patients, a population where a benefit would be observed if truly present. There is an inherent difficulty in assessing pulmonary response in clinical trials, and accordingly, the primary outcome measure is a possible criticism. However, maximal oxygen requirements and $\mathrm{PaO}_{2} / \mathrm{FiO}_{2}$ are well established surrogate markers, ${ }^{45} 46$ and have been used in recent comparable trials. $^{47-49}$

The safety of HDIVZn has been addressed in previous literature. ${ }^{17-20}$ Elemental zinc has been administered at a substantially higher dose (ranging from 26.4 to $37.5 \mathrm{mg} / \mathrm{d}$ for 8 successive days) in the treatment of burns and did not produce any side effects in humans. ${ }^{17-19}$ In the setting of critically ill patients, zinc intravenously at three times higher dose than the current study $(0.75 \mathrm{mg} / \mathrm{kg} / \mathrm{d}$ for 7 days) did not produce any adverse effects. ${ }^{20}$

In conclusion, we designed a single-centre, doubleblind, randomised controlled trial to assess the potential benefit of HDIVZn for hospitalised or critically ill patients with SARS-CoV-2 infection and associated respiratory compromise. We believe that our well-designed trial will be able to expediently identify a potential agent that may improve outcomes for these critically ill patients.

\section{Author affiliations}

${ }^{1}$ Department of Surgery, Austin Health, Heidelberg, Victoria, Australia

${ }^{2}$ Infectious Diseases, Austin Health, Heidelberg, Victoria, Australia

${ }^{3}$ Respiratory and Sleep Medicine, Austin Health, Heidelberg, Victoria, Australia

${ }^{4}$ Intensive Care Unit Austin Hospital, Austin Health, Heidelberg, Victoria, Australia

${ }^{5}$ Department of Medicine, Austin Health, Heidelberg, Victoria, Australia

Contributors MP assisted in protocol design, ethical submission and manuscript production. JEK and VC were involved in data collection and manuscript production. LQ was involved in statistical design and analysis. PJ, JT and CFMD were involved in patient care and study protocol design. DJ, DB, RB, OP and Jl were involved in project design, patient care, manuscript production and supervision.

Funding The authors have not declared a specific grant for this research from any funding agency in the public, commercial or not-for-profit sectors.

Competing interests None declared.

Patient consent for publication Not required.

Provenance and peer review Not commissioned; externally peer reviewed.

Supplemental material This content has been supplied by the author(s). It has not been vetted by BMJ Publishing Group Limited (BMJ) and may not have been peer-reviewed. Any opinions or recommendations discussed are solely those of the author(s) and are not endorsed by BMJ. BMJ disclaims all liability and responsibility arising from any reliance placed on the content. Where the content includes any translated material, BMJ does not warrant the accuracy and reliability 
of the translations (including but not limited to local regulations, clinical guidelines, terminology, drug names and drug dosages), and is not responsible for any error and/or omissions arising from translation and adaptation or otherwise.

Open access This is an open access article distributed in accordance with the Creative Commons Attribution Non Commercial (CC BY-NC 4.0) license, which permits others to distribute, remix, adapt, build upon this work non-commercially, and license their derivative works on different terms, provided the original work is properly cited, appropriate credit is given, any changes made indicated, and the use is non-commercial. See: http://creativecommons.org/licenses/by-nc/4.0/.

\section{ORCID iDs}

Marlon Perera http://orcid.org/0000-0002-1138-6389

Jason Trubiano http://orcid.org/0000-0002-5111-6367

\section{REFERENCES}

$1 \mathrm{Hu}$ Y, Sun J, Dai Z, et al. Prevalence and severity of corona virus disease 2019 (COVID-19): a systematic review and meta-analysis. $J$ Clin Virol 2020;127:104371.

2 Tu H, Tu S, Gao S, et al. The epidemiological and clinical features of COVID-19 and lessons from this global infectious public health event. J Infect 2020.

3 Weston S, Frieman MB. COVID-19: knowns, unknowns, and questions. $m$ Sphere 2020;5. doi:10.1128/mSphere.00203-20. [Epub ahead of print: 18 Mar 2020].

4 Zhu J, Zhong Z, Li H, et al. Ct imaging features of 4,121 patients with COVID-19: a meta-analysis. J Med Virol 2020.

5 Ledford H. How does COVID-19 kill? uncertainty is hampering doctors' ability to choose treatments. Nature 2020;580:311-2.

6 Wang Y, Zhang D, Du G, et al. Remdesivir in adults with severe COVID-19: a randomised, double-blind, placebo-controlled multicentre trial. Lancet 2020;395:1569-78

7 Ischia J, Bolton DM, Patel O. Why is it worth testing the ability of zinc to protect against ischaemia reperfusion injury for human application. Metallomics 2019;11:1330-43.

8 Prasad AS. Zinc is an antioxidant and anti-inflammatory agent: its role in human health. Front Nutr 2014;1:14.

9 Hulisz D. Efficacy of zinc against common cold viruses: an overview. J Am Pharm Assoc 2004;44:594-603.

10 Suara RO, Crowe JE. Effect of zinc salts on respiratory syncytial virus replication. Antimicrob Agents Chemother 2004;48:783-90.

11 Li D, Wen L-zhen, Y uan H. [Observation on clinical efficacy of combined therapy of zinc supplement and jinye baidu granule in treating human cytomegalovirus infection]. Zhongguo Zhong Xi Yi Jie He Za Zhi 2005;25:449-51.

12 Femiano F, Gombos F, Scully C. Recurrent herpes labialis: a pilot study of the efficacy of zinc therapy. J Oral Pathol Med 2005;34:423-5.

13 te Velthuis AJW, van den Worm SHE, Sims AC, et al. Zn(2+) inhibits coronavirus and arterivirus RNA polymerase activity in vitro and zinc ionophores block the replication of these viruses in cell culture. PLOS Pathog 2010;6:e1001176.

14 O'Kane D, Gibson L, May CN, et al. Zinc preconditioning protects against renal ischaemia reperfusion injury in a preclinical sheep large animal model. Biometals 2018;31:821-34.

15 Rao K, Sethi K, Ischia J, et al. Protective effect of zinc preconditioning against renal ischemia reperfusion injury is dose dependent. PLoS One 2017;12:e0180028.

16 Cheung E, Nikfarjam M, Jackett L, et al. The protective effect of zinc against liver ischaemia reperfusion injury in a rat model of global ischaemia. J Clin Exp Hepatol 2020;10:228-35.

17 Berger MM, Baines M, Raffoul W, et al. Trace element supplementation after major burns modulates antioxidant status and clinical course by way of increased tissue trace element concentrations. Am J Clin Nutr 2007;85:1293-300.

18 Berger MM, Binnert C, Chiolero RL, et al. Trace element supplementation after major burns increases burned skin trace element concentrations and modulates local protein metabolism but not whole-body substrate metabolism. Am J Clin Nutr 2007;85:1301-6.

19 Berger MM, Spertini F, Shenkin A, et al. Trace element supplementation modulates pulmonary infection rates after major burns: a double-blind, placebo-controlled trial. Am J Clin Nutr 1998;68:365-71.

20 Cvijanovich NZ, King JC, Flori HR, et al. Safety and dose escalation study of intravenous zinc supplementation in pediatric critical illness. JPEN J Parenter Enteral Nutr 2016;40:860-8.
21 Chan A-W, Tetzlaff JM, Altman DG, et al. Spirit 2013 statement: defining standard protocol items for clinical trials. Ann Intern Med 2013;158:200-7.

22 Institute of Medicine Panel on M. Dietary reference intakes for vitamin $\mathrm{A}$, vitamin $\mathrm{K}$, arsenic, boron, chromium, copper, iodine, iron, manganese, molybdenum, nickel, silicon, vanadium, and zinc. Washington (dC): national academies press (US) Copyright 2001 by the National Academy of sciences. All rights reserved 2001.

23 Solomons NW, Romero-Abal M-E, Weiss G, et al. Bioavailability of zinc from NutriSet zinc tablets compared with aqueous zinc sulfate. Eur J Clin Nutr 2011;65:125-31.

24 Feillet-Coudray C, Meunier N, Rambeau M, et al. Long-Term moderate zinc supplementation increases exchangeable zinc pool masses in late-middle-aged men: the Zenith study. Am J Clin Nutr 2005;82:103-10.

25 Keyzer JJ, Oosting E, Wolthers BG, et al. Zinc absorption after oral administration of zinc sulfate. Pharm Weekb/ Sci 1983;5:252-3.

26 Hempe JM, Carlson JM, Cousins RJ. Intestinal metallothionein gene expression and zinc absorption in rats are zinc-responsive but refractory to dexamethasone and interleukin 1 alpha. J Nutr 1991;121:1389-96.

27 Nair AB, Jacob S. A simple practice guide for dose conversion between animals and human. J Basic Clin Pharm 2016;7:27-31.

28 Bennett JW. Regional body surface area of sheep. J Agric Sci 1973;81:429-32

29 Stehle P, Stoffel-Wagner B, Kuhn KS. Parenteral trace element provision: recent clinical research and practical conclusions. Eur J Clin Nutr 2016;70:886-93.

30 Common Terminology Criteria for Adverse Events (CTCAE v5.0). National Cancer Institute, 2017. Available: https://ctep.cancer.gov/ protocolDevelopment/electronic_applications/docs/CTCAE_v5_ Quick_Reference_8.5x11.pdf

31 Science M, Johnstone J, Roth DE, et al. Zinc for the treatment of the common cold: a systematic review and meta-analysis of randomized controlled trials. CMAJ 2012;184:E551-61.

32 Bhatnagar S, Wadhwa N, Aneja S, et al. Zinc as adjunct treatment in infants aged between 7 and 120 days with probable serious bacterial infection: a randomised, double-blind, placebo-controlled trial. Lancet 2012;379:2072-8.

33 Ferrari E, Wright-Minogue J, Fang JW, et al. Characterization of soluble hepatitis $C$ virus RNA-dependent RNA polymerase expressed in Escherichia coli. J Virol 1999;73:1649-54.

34 Arnold JJ, Ghosh SK, Cameron CE. Poliovirus RNA-dependent RNA polymerase (3D(pol)). Divalent cation modulation of primer, template, and nucleotide selection. J Biol Chem 1999;274:37060-9.

35 Butterworth BE, Korant BD. Characterization of the large picornavira polypeptides produced in the presence of zinc ion. $J$ Virol 1974;14:282-91.

36 Wang L, Song Y. Efficacy of zinc given as an adjunct to the treatment of severe pneumonia: a meta-analysis of randomized, double-blind and placebo-controlled trials. Clin Respir J 2018;12:857-64.

37 Zhu H, Rhee J-W, Cheng P, et al. Cardiovascular complications in patients with COVID-19: consequences of viral toxicities and host immune response. Curr Cardiol Rep 2020;22:32.

38 Feng G, Zheng KI, Yan Q-Q, et al. COVID-19 and liver dysfunction: current insights and emergent therapeutic strategies. J Clin Trans/ Hepatol 2020;8:1-7.

39 Fanelli V, Fiorentino M, Cantaluppi V, et al. Acute kidney injury in SARS-CoV-2 infected patients. Crit Care 2020;24:155.

40 Mubarak M, Nasri H. COVID-19 nephropathy; an emerging condition caused by novel coronavirus infection. J Nephropathol 2020;9:e21.

41 Castro L, Freeman BA. Reactive oxygen species in human health and disease. Nutrition 2001;17:161-5.

42 Lachance PA, Nakat Z, Jeong WS. Antioxidants: an integrative approach. Nutrition 2001;17:835-8.

43 Ruttkay-Nedecky B, Nejdl L, Gumulec J, et al. The role of metallothionein in oxidative stress. Int J Mol Sci 2013;14:6044-66.

44 Prasad AS. Zinc: an antioxidant and anti-inflammatory agent: role of zinc in degenerative disorders of aging. J Trace Elem Med Biol 2014;28:364-71.

45 Matthay MA, McAuley DF, Ware LB. Clinical trials in acute respiratory distress syndrome: challenges and opportunities. Lancet Respir Med 2017;5:524-34

46 Donahoe M. Acute respiratory distress syndrome: a clinical review. Pulm Circ 2011;1:192-211.

47 Frat J-P, Ricard J-D, Quenot J-P, et al. Non-Invasive ventilation versus high-flow nasal cannula oxygen therapy with apnoeic oxygenation for preoxygenation before intubation of patients with acute hypoxaemic respiratory failure: a randomised, multicentre, open-label trial. Lancet Respir Med 2019;7:303-12. 
$48 \mathrm{He} \mathrm{H}$, Sun B, Liang L, et al. A multicenter RCT of noninvasive ventilation in pneumonia-induced early mild acute respiratory distress syndrome. Crit Care 2019;23:300.
49 Pennisi MA, Bello G, Congedo MT, et al. Early nasal high-flow versus Venturi mask oxygen therapy after lung resection: a randomized trial. Crit Care 2019;23:68. 